\title{
Periodontal disease, tooth loss, and oral hygiene among older Americans
}

Brian A. Burt, Amid I. Ismail and Stephen A. Eklund

Program in Dental Public Health, School of Public Health, The University of Michigan, Ann Arbor, Michigan, USA
Burt BA, Ismail AI, Eklund SA: Periodontal disease, tooth loss, and oral hygiene among older Americans. Community Dent Oral Epidemiol 1985; 13: 93-6.

\begin{abstract}
Recent research has suggested that susceptibility to destructive periodontal disease may not be as universal as was previously thought. This report analyzes data from a representative national sample of 11338 American adults aged 25-74, examined in a national survey in 1971-74. Results showed that $46.1 \%$ of those aged 65-74 were edentulous, but half of the dentate persons in that age group were diagnosed as free of destructive periodontal disease. Periodontal (PI) and oral hygiene (OHI-S) index scores in this group were significantly better in those persons who had lost fewest teeth. When persons aged 65-74 who retained 25 or more teeth were compared with younger adults who also had 25 or more teeth, OHI-S and CI scores were similar. It is hypothesized that maintenance of oral hygiene levels corresponding to OHI-S scores of $0.3-0.6$, and calculus levels corresponding to CI scores of $0.1-0.2$, is sufficient to maintain a dentition free of periodontal disease throughout life. Slightly higher OHI-S levels $(0.7-1.3)$ and CI levels (0.3-0.6) might be compatible with acceptably low levels of periodontal disease.
\end{abstract}

Key words: older persons; oral hygiene; periodontal disease; periodontal indexes; tooth loss

Brian A. Burt, Program in Dental Public Health, School of Public Health, Ann Arbor, MI 48109, USA

Accepted for publication 9 April 1984
Susceptibility to destructive periodontal disease may not be as universal as once thought. Studies on the natural history of the condition (1-3), increasing research into the immunologic response (4), and the likelihood that what is called "periodontal disease" may really be a number of different diseases with similar clinical signs (5), have all helped to present the condition in this new light. There is now evidence to suggest that periodontal lesions do not progress at a uniform rate but rather have periods of activity, quiescence and even attachment gain (6-8). HugOSON \& JoRdan (9) in a study in the Swedish city of Jönköping, reported that severity of periodontal disease among dentate subjects aged 20-70 hardly varied with increasing age, although mean tooth loss and the proportion of edentulous persons both increased with age. These findings suggest that some persons are able to maintain a functioning dentition for life, despite the presence of gingivitis. The findings might also mean that some forms of periodontal disease progress to bone loss and subsequent tooth loss while other, apparently similar, forms do not. As a third possibility, perhaps it is oral hygiene alone which largely controls the development of periodontal disease.

This paper examines periodontal dis- ease distribution in a national sample of 11338 adults aged 25-74 in the United States. The data were collected as part of the first National Health and Nutrition Examination Survey (NHANES I) in 1971-74. The purpose of this analysis is to define levels of oral hygiene status compatible with a high degree of tooth retention and an acceptable level of periodontal disease.

\section{Material and Methods}

The NHANES I survey - The National Health and Nutrition Examination Survey (NHANES) is the name given to an intended series of cross-sectional surveys of the American public. They have been developed from the earlier Health Examination Surveys and Health Interview Surveys, and like them are conducted by the National Center for Health Statistics, an agency of the US government. The first of these surveys (NHANES I) was conducted from 1971-74 on a nationally representative sample of 20749 persons aged $1-74$, a response rate of $74 \%$. Detailed descriptions of the design and conduct of the NHANES I survey have been published (10).

Dental data in NHANES I - Caries status was recorded by the DMFT index, periodontal status by the Periodontal In- dex, or PI (11), and oral hygiene status by the Simplified Oral Hygiene Index, or OHI-S (12). The OHI-S is a composite of the Debris Index and Calculus Index (CI). Two senior dentists trained the junior examiners and conducted replicate examinations with them throughout the survey. Descriptive data from the NHANES I survey, including details of the dental examinations and criteria used, have been published $(13,14)$, as have more detailed analyses $(15,16)$.

Statistical analysis - In the NHANES I survey, there was deliberate oversampling of low-income people, preschoolchildren, women of child-bearing age, and those older than $65 \mathrm{yr}$ of age in order to allow special study of those groups. In this report all statistics were computed using sampling weights, and hence the estimates presented can be generalized to the United States population of 1971-74. Significance tests were not included in the tables because for groups of this size even trivial differences are usually statistically significant.

\section{Results}

The broad indicators of periodontal disease follow expected patterns in Table 1 . It can be seen, however, that only just over half of dentate persons aged 65-74 
Table 1. Tooth loss, Periodontal Index scores, and level of periodontal disease in national sample of 11338 adults aged 25-74. United States, 1971-74

\begin{tabular}{|c|c|c|c|c|c|c|c|}
\hline \multirow[b]{2}{*}{$\begin{array}{l}\text { Age } \\
\text { group }\end{array}$} & \multirow[b]{2}{*}{$n$} & \multirow[b]{2}{*}{$\begin{array}{l}\text { Edentulous } \\
\text { percent }\end{array}$} & \multicolumn{5}{|c|}{ Dentate } \\
\hline & & & $\begin{array}{l}\text { Mean no. } \\
\text { of teeth }\end{array}$ & $\begin{array}{l}\text { Mean } \\
\text { PJ }\end{array}$ & $\begin{array}{l}\text { Percent with no } \\
\text { periodontal disease }\end{array}$ & $\begin{array}{l}\text { Percent with } \\
\text { gingivitis }\end{array}$ & $\begin{array}{l}\text { Percent with } \\
\text { pockets }\end{array}$ \\
\hline $25-34$ & 2693 & 3.2 & 25.9 & 0.7 & 57.8 & 28.2 & 14.0 \\
\hline $35-44$ & 2327 & 9.2 & 23.0 & 1.1 & 50.1 & 23.5 & 26.4 \\
\hline $45-54$ & 1598 & 16.1 & 21.7 & 1.4 & 44.3 & 22.0 & 33.7 \\
\hline $55-64$ & 1261 & 33.2 & 19.9 & 1.8 & 42.1 & 16.9 & 41.0 \\
\hline $65-74$ & 3459 & 46.1 & 17.2 & 2.4 & 36.3 & 13.1 & 50.6 \\
\hline
\end{tabular}

Table 2. Mean PI scores and level of periodontal disease in dentate 65-74-yr-olds, according to degree of tooth retention and socioconomic status. United States, 1971-74

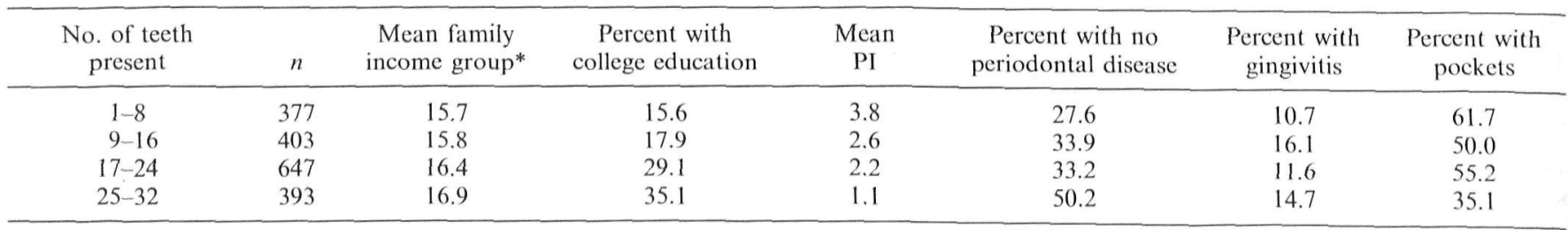

* Total family income was divided into 12 groups in NHANES I starting with group 11 (\$1000 per year or less) to group 22 (\$25 500 per year or more).

were classified as having pockets. Table 2 shows the extent of periodontal disease among the 1820 dentate persons in this oldest age group (65-74) by four categories of tooth retention. Not unexpectedly, both mean PI scores and extent of disease were better with greater tooth retention. What may be unexpected is that $21.6 \%$ of the dentate 65-74-yr-olds still had 25 or more teeth $(23.0 \%$ of women and $20.2 \%$ of men).

Also, Table 2 shows these persons with greater tooth retention to be generally of higher socioeconomic status, and so their superior oral hygiene (Table 3 ) would be expected. OHI-S scores are consistently better for women than men at all levels of tooth retention (data not tabulated), but the overall pattern for men and women separately is the same as shown in the combined group.

The mean PI scores, OHI-S scores, CI scores, and the OHI-S and CI scores of those with 25-32 teeth and those diagnosed as being without periodontal disease in all adult age groups are shown in Table 4. Because there are disproportionately more females in the 65-74 age group compared to the other age groups, data are shown separately for males and females. Table 4 shows that the OHI-S and CI scores for persons classified as having no periodontal disease remain remarkably similar across all age groups.
Table 3. Mean OHI-S scores by degree of tooth retention among dentate 65-74-yr-olds. United States, 1971-74

\begin{tabular}{|c|c|c|c|c|c|}
\hline \multirow[b]{2}{*}{$\begin{array}{l}\text { No. of } \\
\text { teeth } \\
\text { present }\end{array}$} & \multirow[b]{2}{*}{$n^{*}$} & \multirow[b]{2}{*}{$\begin{array}{l}\text { Mean } \\
\text { OHI-S }\end{array}$} & \multicolumn{3}{|c|}{$\begin{array}{c}\text { Mean OHI-S by level of periodontal } \\
\text { disease }\end{array}$} \\
\hline & & & $\begin{array}{l}\text { No } \\
\text { periodontal } \\
\text { disease }\end{array}$ & Gingivitis & Pockets \\
\hline $1-8$ & 57 & 2.0 & 0.7 & 2.0 & 2.4 \\
\hline $9-16$ & 319 & 1.8 & 0.8 & 1.6 & 2.6 \\
\hline $17-24$ & 645 & 1.5 & 0.7 & 1.1 & 2.1 \\
\hline $25-32$ & 393 & 1.0 & 0.4 & 1.3 & 1.6 \\
\hline
\end{tabular}

* Numbers smaller than in Table 2 because of absence of OHI-S index teeth in some subjects.

Table 4. For adults aged 25-74 yr with 25-32 teeth: Mean PI, OHI-S, and CI scores. Also OHI$\mathrm{S}$ and CI scores for persons without periodontal disease. United States, 1971-74

\begin{tabular}{|c|c|c|c|c|c|c|c|}
\hline & \multirow[b]{2}{*}{$\begin{array}{l}\text { Age } \\
\text { group }\end{array}$} & \multicolumn{3}{|c|}{$\begin{array}{c}\text { Persons } \\
\text { with and without } \\
\text { periodontal disease }\end{array}$} & \multicolumn{2}{|c|}{$\begin{array}{l}\text { Persons without } \\
\text { periodontal disease }\end{array}$} & \multirow[b]{2}{*}{$\begin{array}{l}\text { Mean } \\
\text { CI }\end{array}$} \\
\hline & & $\begin{array}{l}\text { Mean } \\
\text { PI }\end{array}$ & $\begin{array}{c}\text { Mean } \\
\text { OHI-S }\end{array}$ & $\begin{array}{l}\text { Mean } \\
\text { CI }\end{array}$ & $\begin{array}{l}\text { Percent } \\
\text { of total } \\
\text { dentate }\end{array}$ & $\begin{array}{l}\text { Mean } \\
\text { OHI-S }\end{array}$ & \\
\hline \multicolumn{8}{|l|}{ Men } \\
\hline & $25-34$ & 0.7 & 1.0 & 0.4 & 55.9 & 0.6 & 0.2 \\
\hline & $35-44$ & 0.9 & 1.1 & 0.5 & 52.9 & 0.5 & 0.2 \\
\hline & $45-54$ & 1.1 & 1.2 & 0.6 & 46.0 & 0.5 & 0.2 \\
\hline & $55-64$ & 1.4 & 1.1 & 0.5 & 41.9 & 0.5 & 0.1 \\
\hline & $65-74$ & 1.4 & 1.3 & 1.3 & 39.7 & 0.6 & 0.2 \\
\hline \multicolumn{8}{|l|}{ Women } \\
\hline & $25-34$ & 0.4 & 0.8 & 0.3 & 66.6 & 0.4 & 0.1 \\
\hline & $35-44$ & 0.6 & 0.7 & 0.3 & 62.5 & 0.3 & 0.1 \\
\hline & $45-54$ & 0.8 & 0.8 & 0.3 & 54.8 & 0.4 & 0.2 \\
\hline & $55-64$ & 0.8 & 0.8 & 0.4 & 58.4 & 0.3 & 0.1 \\
\hline & $65-74$ & 0.9 & 0.8 & 0.4 & 57.1 & 0.4 & 0.1 \\
\hline
\end{tabular}




\section{Discussion}

The traditional view about periodontal disease is that it increases with age in a more-or-less linear fashion and that all persons are more-or-less susceptible. This belief has come from both epidemiologic studies and clinical observations (17) over the last $25 \mathrm{yr}$ or so. Increasing edentulousness with age is usually assumed to reflect the ultimate ravages of destructive periodontal disease, and greater mean tooth loss and mean PI scores in older age groups are usually taken to indicate advancing disease among those who have managed to retain some of their teeth.

While there is some truth in these broad generalizations, they can also mask some useful information on disease distribution. The $46.1 \%$ edentulousness in the 65-74 yr-olds, for example (Table $1)$, reflects many things that happened in years gone by: the prevalence and intensity of oral disease suffered many years ago, the availability of care at the time, past economic and social conditions (such as the economic depression of the 1930s and World War II), and the nature and philosophy of dental care provided in other days. It can be predicted that the 25-34-yr-old cohort in Table 1 will be less than $46.1 \%$ edentulous when it is the 65-74-yr-old cohort, if only because many of the current 65-74-yr-olds were rendered edentulous during the time when the "focal infection" theory dominated dental treatment in the United States (18).

Some comments must be made on the method of collecting the NHANES I data. First, there are likely to be both false positive and false negative diagnoses in the assessment of pockets (Table 1), but so long as the examiners were consistent in their diagnoses the distribution of disease shown in Table 1 would still be valid in a sample of this size. Second, the PI has long served its defined purpose as an index capable of being applied in all kinds of field conditions to provide broad comparisons between population groups. Much of what is now basic knowledge of periodontal disease has come from surveys in which the PI was used. But although its validity at the time of its development was extensively assessed against clinical diagnoses (11), questions can be raised about its present day validity in light of recent findings on periodontal pathology. Perhaps the PI is now ready to join those other indices which have served well, but which are no longer suitable for addressing present day questions.

The data presented in this analysis show that $21.6 \%$ of dentate Americans aged 65-74 still had 25 or more teeth. That could be due to greater inherent resistance to destructive disease, but it probably is more likely to be the result of excellent oral hygiene. The past explanation is enhanced by the information in Table 4, which shows that for persons with 25-32 teeth, oral hygiene levels, and CI scores in particular, are remarkably similar among adults of all ages.

The data do show clearly that loss of teeth from destructive periodontal disease in old age is not inevitable, regardless of the reason why. They also show (Table 4) that even if PI scores increase with age, this increased gingivitis and pocketing does not necessarily equate with tooth loss so long as oral hygiene is maintained. Where excellent oral hygiene is maintained, age does not seem to be an important independent variable in periodontal disease status.

Given that these data are now more than $10 \mathrm{yr}$ old, it is possible that the proportion of older Americans with good periodontal health has altered. The direc- tion of any change, however, remains uncertain until the next national survey is completed.

We stated at the beginning of this paper that its purpose was to define levels of oral hygiene compatible with tooth retention and an acceptable level of periodontal disease. While the preceding discussion tells us that the nature of the disease still needs a great deal of definition, the role of oral hygiene in its development is not in question. Within the limitations imposed by our imperfect knowledge of the natural history of periodontal disease, we can hypothesize that oral hygiene status relating to OHI-S values of $0.3-0.6$, or perhaps more importantly to CI levels of $0.1-0.2$, might be compatible with virtual absence of destructive periodontal disease throughout life for most people. Slightly higher levels of calculus (CI scores 0.3-0.6) and OHI$\mathrm{S}$ scores of $0.7-1.3$ are associated with low-to-moderate levels of periodontal disease, but these levels still seem compatible with retention of teeth.

Acknowledgments - The original data for this paper were supplied by the National Center for Health Statistics. Results of analysis and conclusions reached are solely those of the authors.

\section{References}

1. LÖe H, ANERud A, Boysen H, Smith M. The natural history of periodontal disease in man: study design and baseline data. J Periodontal Res 1978; 13: 550-62.

2. Löe H, ANERud A, Boysen H, Smith M. The natural history of periodontal disease in man: the rate of periodontal destruction before 40 years of age. J Periodontal Res 1978; 49: 607-20.

3. Anerud A, Löe H, Boysen H, Smith M. The natural history of periodontal disease in man. Changes in gingival health and oral hygiene before 40 years of age. $J$ Periodontal Res 1979; 14: $526-40$,

4. LEHNER T. Future possibilities for the prevention of caries and periodontal disease. $\mathrm{Br}$ Dent $J$ 1980; 149: 318-25.

5. PAGE RC. Periodontal research. Implications for the future of academic dentistry. $J$ Dent Educ 1983; 47: 226-31.

6. Haffajee AD, Socransky SS, Goodson JM. Periodontal disease activity. $J$ Periodontal Res 1982; 17: 521-2.

7. Goodson JM, Tanner ACM, Haffajee AD, Sornberger GC, Socransky SS. Patterns of progression and regression of advance destructive periodontal disease. J Clin Periodontol 1982; 9: 472-81.

8. Lindhe J, Haffajee AD, Socransky SS. Progression of periodontal disease in adult subjects in the absence of periodontal therapy. J Clin Periodontol 1983; 10: 433-42.

9. Hugoson A, JoRDAN T. Frequency distribution of individuals aged 20-70 years according to severity of periodontal disease. Community Dent Oral Epidemiol 1982; 10: 187-92.

10. Miller H. Plan and operation of the health and nutrition examination survey: United States - 1971-1974. Hyattsville, Maryland: National Center for Health Statistics, 1979; DHEW publication No. (PHS) 73-1310. (Vital and Health Statistics; Series 1; Nos. 10a and 10b).

11. Russell AL. A system of classification and scoring for prevalence surveys of periodontal disease. J Dent Res 1956; 35: 350-9.

12. Greene JC, Vermillion JF. The simplified oral hygiene index. J Am Dent Assoc 1964; 68: $7-13$.

13. Kelly JE, Harvey CR. Basic data on dental examination findings of persons 1-74 years: United States - 1971-1974. Hyattsville, Maryland: National Center for Health Statistics, 
1979; DHEW publication No. (PHS) 79-1662. (Vital and Health Statistics; Series 11; No. 214).

14. Harvey C, Kelly JE. Decayed, missing and filled teeth among persons 1-74 years: United States - 1971-1974. Hyattsville, Maryland: National Center for Health Statistics, 1981; DHHS publication No. (PHS) 81-1673. (Vital and Health Statistics; Series 11; No. 223).

15. Burt BA, EKLUnd SA, LANdis JR, LARKin FA, Guire KE, Thompson FE. Diet and dental health, a study of relationships: United States - 1971-1974. Hyattsville, Maryland: National Center for Health Statistics, 1982; DHHS publication No. (PHS) 82-1675. (Vital and Health Statistics; Series 11; No. 225).

16. Ismail AI, BURT BA, EKLUND SA. Epidemiologic patterns of smoking and periodontal disease in the United States. J Am Dent Assoc 1983; 106; 617-21.

17. Becker W, Berg L, BeCKer BE. Untreated periodontal disease. A longitudinal study. $J$ Periodontol 1979; 50: 234-44.

18. BURT BA. Influences for change in the dental health status of populations. An historical perspective. J Public Health Dent 1978; 38: 272-88. 
This document is a scanned copy of a printed document. No warranty is given about the accuracy of the copy. Users should refer to the original published version of the material. 